\title{
Why do we do it?
}

\author{
Stephen Hancocks OBE \\ Editor-in-Chief
}

The BDJ Upfront section includes editorials, letters, news, book reviews and interviews. Please direct your correspondence to the News Editor,

Adrian O'Dowd at BDJNews@nature.com. Press releases or articles may be edited, and should include a colour photograph if possible.

S ome years ago I was asked to give a lecture to what were then called vocational trainees (VTs) on career development. I happily set off describing how dentistry was a great choice because it was unusual among occupations in that one could mould one's work around one's life rather than having, necessarily, to make one's work dictate one's life. To be honest, few of the recently qualified colleagues seemed much impressed. They had become dentists with the express idea of doing dentistry; pretty much the same motivating force that my peers had expressed some two decades previously.

I carried on as before, and I am guessing they carried on as before and the organisers of the VT scheme carried on as before - and invited me back the following year. And the following year. And so on; I think for about eight or so annual visits. I am not sure if they were being kind, or if they just needed something a little different to fill the end of term programme or, actually, if they were considerably more far sighted than most. You see what I gradually noticed happening in successive presentations was that the mood of the audience shifted from 'who is this heretic and why is he suggesting that we could take up all these other weird things?' to: 'yes we know these things are possible, and desirable, and that's why we did dentistry'. Eventually I was telling them nothing that they hadn't worked out for themselves. Broadly speaking. I am sure the majority of them are practising dentistry but many of them, I suspect, are also enjoying other aspects of life as a result of the flexibility that being in such a profession allows if you choose it to.

The recollection of this was prompted recently when talking to dental students on 'how to get published' (a regular request from dental schools and one we are happy to fulfil). Frankly, such requests were unheard of in the past. The very idea of dental writing, or dental journalism was so off the radar that I doubted we would ever find new authors, let alone young ones. So what has changed? Two things I think: the world in which we live and the dental students of today/dentists of tomorrow who inhabit it.

If I was to ask you right now to list the changes that have taken place in your own practising lifetime you will either reach for a pen and paper or a keyboard and screen (which immediately delineates a major transitional change). You will be amazed at the list, even if you qualified recently. Legislation, regulation, clinical technique, implants, electric cars, mobile phones, the internet, the Brexit referendum, Woolworths closing, interdental brushes...
There is doubtless some bedrock of the generation gap in play too but the divide can cause both friction and I would also suggest understanding, and if we allow it, mutual inspiration. I suspect that these forces were in play, for example, in a paper we published on the subject of what foundation dental trainers thought of their trainees. ${ }^{1}$ The results showed a curious dichotomy in that less than half of the trainers (43\%) thought their trainees were prepared for practice, but the majority (55\%) of the same trainers expressed a wish to employ their trainees if it were possible. Such an apparent contradiction points to both a sneaking regard for each other's skills, abilities and outlooks as well as an almost parental desire for encouragement towards betterment.

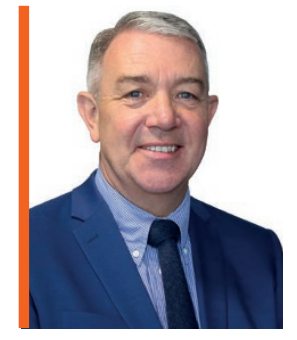

\section{'By raising the level of grades we have also influenced and determined the calibre and type of young person we have attracted'}

Each item on your list will have had a direct or indirect effect on our young colleagues, not to mention what motivated them to become dentists and what qualifications they needed to get to dental school in the first place. As time has gone by 'our' focus (the established profession) has shifted to make this more difficult in order to attract 'the best'. By raising the level of grades we have also influenced and determined the calibre and type of young person we have attracted. The consequences are that whether one dubs the cohorts as millennials or generation $\mathrm{Z}$ or any other epithet, the outlook and life experience, that is experience of their lives thus far, is crucially different to, how may I write it politely? more mature colleagues.
What I haven't mentioned yet at all is the primary focus of these important developments - patient care. Because the same list of changes has affected patients too and the same basic elements that made them 'trust us' in the past are still in place today. The delivery methods have changed but the humanity has not. And that, I think, is why dentistry continues to attract people who are essentially the same but importantly different too. Which is probably the reason why we do it.

1. Hanks S, Coelho C, Coster R. Prepared for practice and equipped for employment: what do dental foundation trainers think of their trainees? Br Dent J 2018; 225: 549-555. 